\title{
Influence of Voltage Sags on the Continuity of the Operation and Lifespan of Single-Phase Industrial Robots
}

\author{
Grzegorz Putynkowski ${ }^{1, *(D)}$, Krzysztof Woźny ${ }^{1}$, Elzbieta Szychta ${ }^{2}$ and Leszek Szychta ${ }^{2}$ D \\ 1 CBRTP S.A. Research and Development Center of Technology for Industry, Waryńskiego 3A, \\ 00-645 Warsaw, Poland; krzysztof.wozny@cbrtp.pl \\ 2 Faculty of Telecommunications, Computer Science and Electrical Engineering, UTP University of Science and \\ Technology, al. prof. S. Kaliskiego 7, 85-796 Bydgoszcz, Poland; elzbieta.szychta@utp.edu.pl (E.S.); \\ leszek.szychta@utp.edu.pl (L.S.) \\ * Correspondence: grzegorz.putynkowski@cbrtp.pl
}

check for updates

Citation: Putynkowski, G.; Woźny, K.; Szychta, E.; Szychta, L. Influence of Voltage Sags on the Continuity of the Operation and Lifespan of Single-Phase Industrial Robots. Coatings 2021, 11, 1229. https:// doi.org/10.3390/coatings11101229

Academic Editor: Ajay Vikram Singh

Received: 10 August 2021

Accepted: 28 September 2021

Published: 9 October 2021

Publisher's Note: MDPI stays neutral with regard to jurisdictional claims in published maps and institutional affiliations.

Copyright: (c) 2021 by the authors. Licensee MDPI, Basel, Switzerland. This article is an open access article distributed under the terms and conditions of the Creative Commons Attribution (CC BY) license (https:/ / creativecommons.org/licenses/by/ $4.0 /)$.

\begin{abstract}
Due to the increase in the number of automated processes that employ industrial robots (especially in industrial and laboratory environments, including vacuum systems), and the resulting increase in the number of unresolved service requests, the purpose of the authors' research was to confirm the occurrence of disturbances in the form of voltage sags that are not recorded by automation systems and which lead to the destruction of robots or their equipment in areas defined by the characteristics of ITIC/SEMI F47 and CBEMA as being free from such disturbances. The article also describes the environmental classification of robots by their process functionalities/features, and recommends equipment that is able to compensate for these disturbances. Such a classification approach can be an excellent tool for building an exploitation culture and assist the conscious selection of electrical equipment in robotised systems susceptible to disturbances (e.g., robots in load-lock in vacuum environment).
\end{abstract}

Keywords: robots destruction; electromagnetic compatibility; resistance of electrical equipment; sag; vacuum environment

\section{Introduction}

As part of their research and development work, the authors sought answers to the question of how voltage sags affect the continuous operation and lifespan of single-phase industrial robots with a lifting capacity of up to $10 \mathrm{~kg}$. The research was conducted in six group ranges of time and sag depth from $0 \%$ to $99 \%$ with a $1 \%$ supply power surge. Based on the results of the experimental test, the effects of voltage sags-the most common form of disturbance to power quality-on the continuous operation of industrial robots was analysed, taking into account the likelihood of the destruction of the robots. The authors juxtaposed the test results with the SEMI F47/ITIC characteristics that revealed destructive conditions for power receivers (20-500 ms at voltage dips of over $70 \%$ ), defined as being free from damage. Disturbances were also identified in the operation of the automation systems, including error loggers, which, due to collapse, fail to record changes in the position of the robot arm in space (distorted position of the encoders), which may result in unforeseen consequences of permanent damage to the unit or its surroundings, which is new knowledge in the discipline. Taking into account the occurrence of destructive conditions, a matrix was developed for industrial robotic systems in relation to standard PN-EN 61000-2-4 [1].

Technological process equipment manufacturers often refer to relevant standards, declaring that their equipment can operate in a disturbed environment [2,3]. However, at present many devices are made up of numerous complex components, such as control systems, manipulators and actuating elements. This often misleads potential users when determining the resistance class and emission of the device as a whole. Interpretive errors 
are due to the fact that manufacturers declare that the devices comply with the standard, while not all of the components can operate in a given environment with the same degree of disturbance [4,5].

The literature often cites device resistance classifications such as TIC/SEMI F47 and CBEMA voltage tolerance curves. At this point, it should be emphasised that, although the topic is extremely important, only a small number of publications describe the problem of the source itself, drawing solutions as well. Unfortunately, this state of affairs results from the nature of the involvement of research groups in this area, which usually work for the manufacturer of robots or peripheral equipment (such as grippers and actuatorsincluding welding, detection, laser, etc.), which is associated with a total ban on disclosing information about their results, including identified problems. There is a perspective that the increasing presence of robotic equipment in the laboratory infrastructure allows for the conclusion that problems resulting from disturbances in their work (especially those leading to the destruction of the robot itself or its periphery) will raise questions and the inquisitiveness of the scientific operator, which will allow for further research into their formation. The subject curiosity and scientific inquisitiveness also lie at the basis of research work aimed at finding answers to whether and to what extent one of the many disturbances in energy quality in the form of voltage dips may damage the electrical receiver (in this case single-phase industrial robots). As a result of the research work carried out and the analysis of their results, not only was the negative impact of stress dips on the durability of industrial robots confirmed as significantly broader than expected, but it was also identified that the disturbances leading to this damage were found in areas defined as free from such conditions. In this context, the authors decided to make the discovery public, hoping that it would trigger a wide-ranging discussion on the need to continue research in this area, taking into account all types of electrical energy disturbances, including those in the group of three-phase robots.

It is also highly probable that the current ITIC/SEMI F47 resistance curves do not reflect problematic phenomena leading to receiver damage, which results from significant progress in the area design and the production of power supply systems, power electronics or automation and control. This progress involves many problematic phenomena that were not taken into account at the time when the above-mentioned characteristics were designed, which, as the authors showed, increased the risk of destructive disturbances in the area. Thus far, these risks been defined as possibly causing electrical energy disturbances, leading to disturbances in the operation of the electrical receiver, but never resulting in damage to the electrical receiver.

The above problems and the increasing incidence of misdiagnosed abnormal conditions in industrial robots (service requests based on incorrect logging of a disturbance source) focused research efforts on looking for incidents with incorrect logging by the robot automation system and determining their effects on the risk of damage to the robot, as well as confirming the occurrence of destructive conditions in areas defined by ITIC/SEMI F47 and CBEMA characteristics as being free from such disturbances. In addition, the authors proposed the use of a matrix for the environmental classification of industrial robots and their equipment in order to select a robot according to the working conditions and, more importantly, in order to choose electrical/power equipment that would compensate for the negative effects of voltage sags on the continuous operation or lifespan of the robotic cell.

As part of the authors' research work, which is presented in earlier studies [6], the project team proposed an environmental classification matrix (Appendix A) for the continuous operation of single-phase industrial robots with a lifting capacity of up to $10 \mathrm{~kg}$. This results in the superiority of the process functionalities and features of the robot and enable the division of the robots into the following three classes:

Class I-required continuous operation (fully automatic process) for the correct implementation of the manufacturing process in which the robot is installed; 
Class II-required stability of operation in the process in which the robot is installed (operation in interrupted cycles where there is a pause between cycles and where another non-automated operation occurs between cycles-a semi-automatic process);

Class III-required stability during the implementation cycle (individual process in which the robot performs a specific action throughout the non-automatic process-robotic technology islands).

Consequently, when used in combination with the electromagnetic resistance classes, electrical equipment that limits or completely compensates for voltage sags and other disturbances in power quality can be properly selected. In relation to the work carried out, the results of which are presented in this article, the classification matrix is restricted to merely assess quality disturbances in the form of voltage sags (as these are the most common disturbances in power quality).

For the first environmental class, equipment was assigned with the highest level of assurance that the process would be maintained in continuous operation despite the occurrence of deep voltage sags and even micro power outages, including standby power and accessories in the form of voltage conditioners such as AVR (Automatic Voltage Regulator), DVR (Dynamic Voltage Restorer), DySC (Dynamic Voltage Sag Corrector), UPS online (Uninterruptible Power Supply), cross-emission reduction in the robot environment, and both passive and active filters.

For the second class, the following two subgroups can be distinguished:

- Group 1-which allows for power outages that do not cause significant problems in the manufacturing process, requiring at least emergency power (short-term support) and accessories in the form of voltage conditioners such as AVR, DVR, DySC, Online UPS, cross-emission reduction in the robot environment, and both passive and active filters;

- Group 2-which allows for incidents that cause robot automation to reset cyclically, while the manufacturing process permits such incidents.

No provision for auxiliary equipment is made for the final environmental class (Class 3), which by nature of the process allows the robots to be automatically reset on the production line without the consequences of interrupting the process or having to stop the entire manufacturing process. However, due to the potential for serious disturbances in logging errors and information regarding the robot interior equipment condition, it is recommended to introduce a position measurement support system based on the external source (e.g., passive optical system) to additionally control the condition of the arm and modulators during and after resetting.

The full classification matrix is presented in Appendix A of this publication.

The research confirmed the occurrence of conditions which eventually lead to damaging a robot/its surroundings or to a health- or life-threatening situation for operators and/or technical services, although, in theory and in accordance with the normative guidelines and the ITIC/SEMI F47 and CBEMA characteristics, the occurrence of such a disturbance should not lead to the destruction of the receiver. Thus, the research identified a major defect in the certification and testing system of power receivers for Class 3 electromagnetic resistance (commissioning a receiver which is damaged despite the proven resistance to destruction in the acceptance tests), which is characteristic of receivers operating in highly disturbed environments.

The literature on the subject, although not very extensive (which is due to the specific character of research work conducted by research groups contracted by international corporations that are industrial robot manufacturers and the nature of their extremely strict confidentiality clauses) clearly indicates the occurrence of problems in maintaining the operating parameters (e.g., peripheral components, such as manipulators, external sensory systems, etc.) as a result of voltage sags. There is a common phenomenon resulting from the differences in the classes of electromagnetic resistance between a robot and its equipment [7]. The authors of the article "Effects of Voltage Dips on Robotic Grasping" discuss the effects of disturbances in power quality on robot performance, with particular 
emphasis on the effects of voltage sags on the robot supply system and auxiliary equipment from the point of view of the end user/operator. In the opinion of the authors, it is reasonable to conduct independent research in this field and on its basis build new standards for testing and commissioning receivers, such as industrial robots. The current normative guidance-based procedures treat peripherals and robots independently, which seems to be a flawed approach, as in extreme cases this can lead to the repair of a robot being refused due to the use of different EMC resistance classes. As this article and the cited publications show, this is an extremely important problem in terms of the effective exploitation of dynamically developing robotic environments, which justifies the undertaking of further work on the cumulative effects (not only voltage sags) of disturbances to power quality on the lifespan and stability operation of high power three-phase industrial robots.

\section{Materials and Methods}

The specification of robotic positions in the context of power conditions for industrial robots should be considered individually for the applied robot architecture. During the research, the authors considered several different systems, presented below, as the article is focused on the problem of the power supply conditions of a single robotic socket dedicated to precision works with the use of single-phase robots with a lifting capacity of up to $10 \mathrm{~kg}[8]$.

Circuits with a single-phase robot for which the impact of disturbances in the powerquality parameters of electricity were considered:

- a single robotic station,

- a station connecting several keypads to one controller,

- a station equipped with one controller but with each manipulator having its own automation of drive control,

- $\quad$ synchronised single robotic stations, each equipped with a separate controller which uses coordinated programming.

It should be noted here that all incidents from the power supply network from the power utility company that disrupted the operation of a single robotic station were recorded in cases of the combined work of many manipulators. In the case of an internal power supply network in which there are many robotic positions, the phenomenon of the propagation of disturbances from one robotic station to the other was also identified. In view of the above, the authors of the article presented the problem of the impact of electricity of poor quality, and, more specifically, the occurrence of voltage dips on robotic sockets in the example of individual robot positions of various companies.

In the case of a common point of connecting consumers to distribution networks, distribution system operators (DSO) are obliged to ensure a certain quality of electrical supply in accordance with the applicable requirements [9]. In Poland, this is the Regulation of the Minister of Economy of 4 May 2007 on detailed conditions for the operation of the power system (RGM), which is based on the old version of the EN 50160 standard-supply voltage parameters for public electricity grids. The current version of EN 50160 [10], as amended, differs in many ways from RGM. Whereas, in the considerations of powering robotic sockets in industrial production lines, power supply parameters should be considered in accordance with IEC 61000-2-4 [1] electromagnetic compatibility (EMC)-part 2-4: environment-compatibility levels in industrial plants for low-frequency conducted disturbances. According to the aforementioned documents, the quality parameters that are accepted by the devices may significantly differ from those required by the arrangement of computer equipment, along with their progress in miniaturisation [11-13]. Disturbances in the supply voltage outside the area specified by the standards may have the following effects $[3,6,14]$ :

- disruption of devices,

- damage to sensitive data processing devices controlling processes,

- $\quad$ speed changes of drive units,

- data processing and measurement errors, 
- control errors,

- overheating of motors, capacitors and transformers,

- flickering of light.

The effects cited are only a small percentage of the unfavourable phenomena. Bear in mind that even during the normal operation of the power system (no emergency states), there are many factors affecting the operation time and the possibility of destroying sensitive receivers. In the case of industrial plants, there are also additional phenomena caused by the receivers themselves, such as start-ups of drives, switching on and off of high-power devices (dips, overvoltages) and emergency states $[15,16]$. With increasing frequency, industrial plants use devices with high sensitivity, such as:

- control systems of production processes,

- computers and servers,

- telecommunications devices,

- protection and security systems,

- automation and robotics devices,

- HMI systems,

- diagnostic and health equipment,

- cash registers and vending machines,

- electronic clocks.

Significant events for the continuity of work in industrial plants are voltage dips and increases. In the case of a decrease in the voltage amplitude, there may be various causes, e.g., a sudden increase in load caused by the start-up of high-power receivers, such as motors, blowers and heating systems as well as emergency states and short circuits $[17,18]$. The source of such an event may be the national power grid, but in the vast majority of cases, it is the recipient itself. A reduction of the effective voltage value causes a disturbance in the operation of devices that are not equipped with energy stores, such as capacitors or accumulators. The next type of event is an increase of voltage amplitude-in this case, the source may be a sudden reduction of the load, damage to the neutral conductor, or atmospheric discharges. Permissible changes in the voltage of the computer hardware as a function of time are presented on the ITIC curve in Figure 1. The area of voltage changes in which the devices work correctly is highlighted in green, and it should be noted that short increases and voltage dips are permitted. The prohibited area is marked in orange; this condition causes faster wear and may destroy the device in the longer term. The blue area is marked as an area where theoretically there is no risk of damage to the device, but it can cause its emergency operation. In Figure 1, a yellow dotted area is marked as an area that is particularly susceptible to disturbances, and at the same time, it is significant from the point of view of the stability of industrial robots and the number of disturbances and interruptions in their work. This area is the main point of interest due to the increase in the number of power electronics devices in power grids which causes frequent exceedances of the ranges specified in the standards, thus generating many operational problems which, in the search for the optimisation of industrial processes using robotic tools, constitute a significant technological problem [19]. The current standard guidelines for tests permitting the operation of industrial robots (especially in the field of electromagnetic compatibility) need to be extended because they do not guarantee the maintenance of reliability, stability and continuity of operation in environments with unstable power-supply parameters.

Initially, in the identification of the problem of improving power-supply conditions of single-phase industrial robots with a lifting capacity of up to $10 \mathrm{~kg}$, a broad review of the prevailing literature was conducted, on the basis of which the ranges of disturbances and the conditions in which they occur were distinguished. On the basis of elaborated assumptions and the parameters of electromagnetic compatibility specified in the norms and other documents, the conditions or the occurrence of the dips phenomenon, including separation of unidentified states leading to the total disruption of the robotic unit operation, were then determined. Subsequently, experimental work was performed under laboratory conditions allowing the simulation of operating conditions and the acquisition of measurement data 
sets of voltage and other power parameters of the tested units. A diagram of the devices used to conduct the tests is presented in Figure 2, followed by a brief description of the equipment.

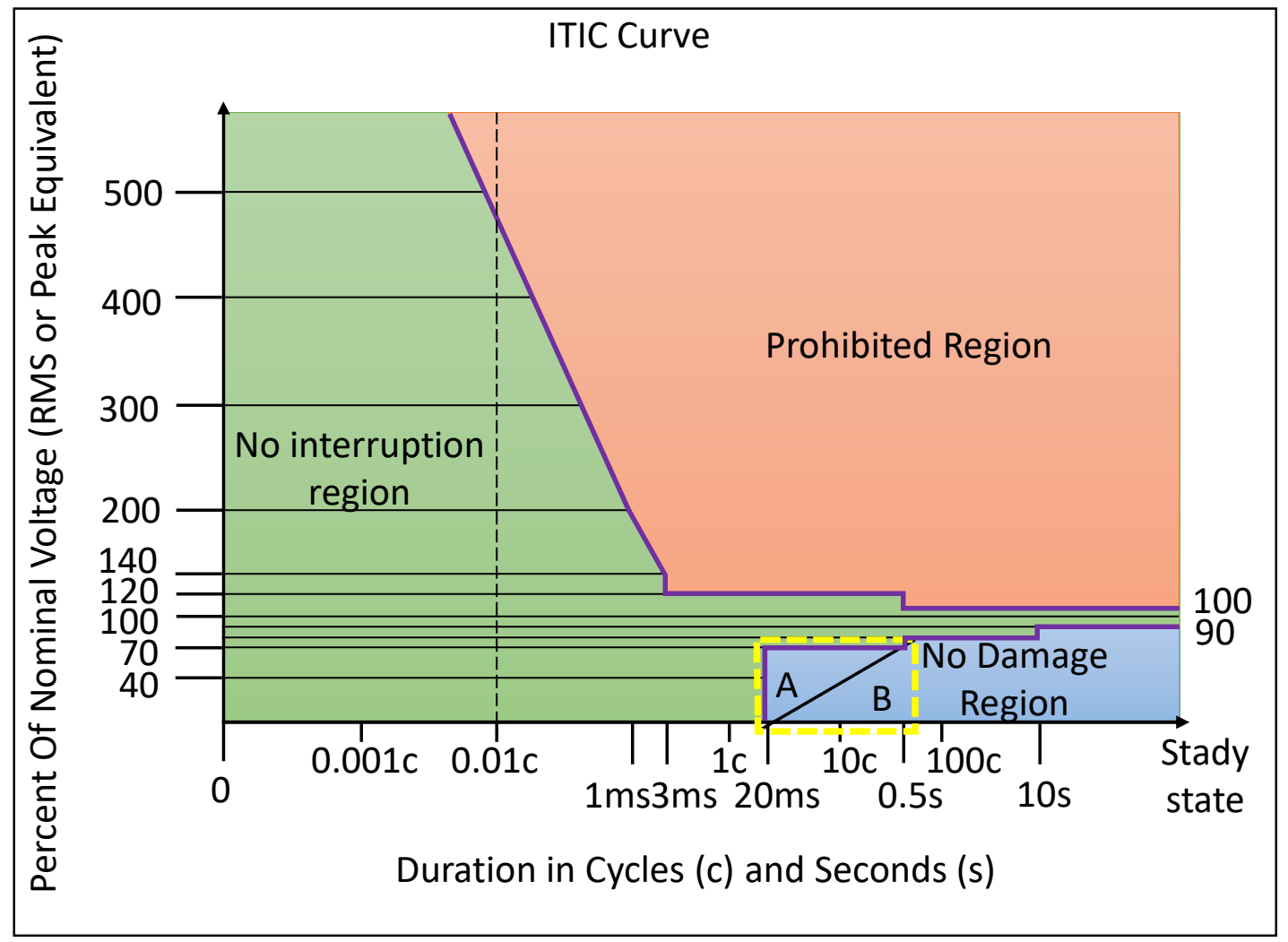

Figure 1. ITIC/SEMI F47 curve describing the permissible range of changes in the voltage supplying the IT device as a function of time (the area marked with a dashed yellow line revealed the forbidden states).

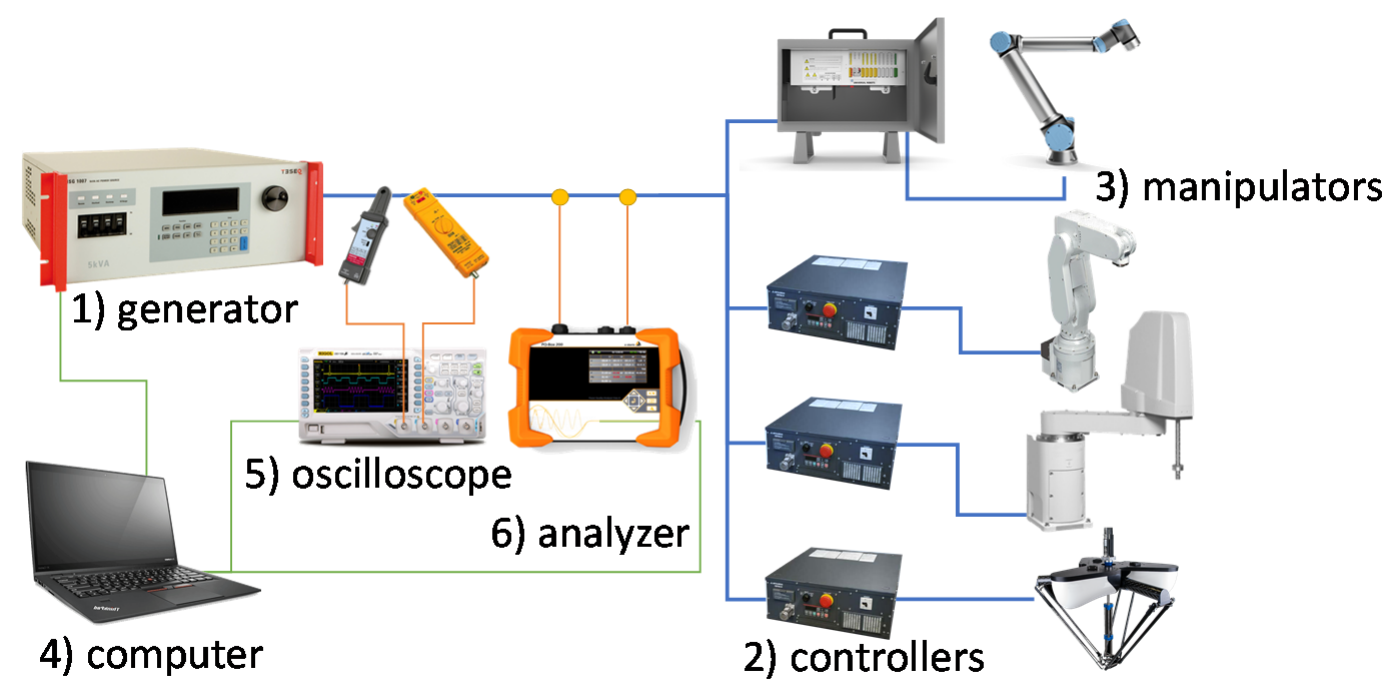

Figure 2. Diagram of the measuring system used to determine the allowable changes in IT equipment voltage as a function of time. 
1. The Teseq NSG 1007 series (Teseq, Luterbach, Switzerland) source which has high efficiency and a lightweight AC and DC power source, which includes high-performance power analysers;

2. Robotics manipulator controller;

3. Robotic socket (various manipulator variants);

4. PC with WIN 2110 generator software for sag design and RIGOL UltraScope registration software, MATLAB software for post-processing of collected results;

5. DS4014E oscilloscope (RIGOL Technologies, Co. Ltd. Beijing, China) with DP-200pro Pintek high-voltage differential probe-1600 Vpp;

6. The A. Eberle GmbH PQ-Box 200 mobile power quality network analyser (A. Eberle, Nürnberg, Germany).

The initial tests were mainly performed in a system with one controller and manipulator, and after verification of the impact on one nest, tests with several robots were launched.

During the study, disturbances in the form of sags were generated, and they were then recorded with the oscilloscope and the analysis of the quality of electricity. The messages of the automation of industrial robots were then read and correlated with the events.

The research on the effect of voltage dips on the robotic units was conducted for the duration of the voltage dip, from $20 \mathrm{~ms}$ to $1 \mathrm{~min}$. In order to simplify the analysis of test results, six time intervals were introduced, with individual time groups divided into four or five time intervals as follows:

- group A-duration of the dip was 20-100 ms-5 intervals every $20 \mathrm{ms,}$

- group B-duration of the dip was 200-500 ms-4 intervals every $100 \mathrm{ms,}$

- group C-duration of the dip was 0.6-1 s-5 intervals every $0.1 \mathrm{~s}$,

- $\quad$ group D-duration of the dip was 1.5-3 s-4 intervals every $0.5 \mathrm{~s}$,

- $\quad$ group E-duration of the dip was 4-20s-5 intervals every $4 \mathrm{~s}$,

- $\quad$ group F-duration of the dip was 30-60s-4 intervals every $10 \mathrm{~s}$.

Next, for each group, an iteration of one hundred measurements was performed where, in each subsequent iteration, the voltage dip was increased by $1 \%$ (0-99\%).

The correctness of the test was verified using an oscilloscope and a power-quality analyser.

The authors decided to supplement the results obtained during the tests using the system presented in Figure 2 with the results of the work using the selected and the most universal DVR voltage sag compilation system. The intention of the authors was to present confirmation of the effectiveness of the compilation process with the use of the DVR system. One of the authors' earlier studies defined the problems of powering the industrial robots used in the welding process [20]. At that time, the methods for limiting the impact of poor power quality on robotic sockets were presented. The authors of this study focused on the issue of reducing dynamic network states, particularly voltage dips. One method of conditioning the supply voltage is the use of dynamic voltage restoration (DVR) [21]. This device is used to stabilise the supply voltage and eliminate the negative effects of voltage disturbances, not only those such as dips and voltage drops but also increases and, in particular cases, fluctuations. Devices of this type are used, in particular, in the security of production lines where the occurrence of any interruption in the operation of one critical device may result in interrupting the entire production process. Due to their design, these devices can be used in places where UPS type solutions cannot be used due to the size of the energy storage elements and the need to provide appropriate explosion zones and storage conditions. Subsequently, a study using one of the conditioners was presented in order to consider the possibility of reducing the impact of voltage dips on production lines.

A general diagram of the device for improving power supply is presented in Figure 3, while the schematic drawing of the measuring system is shown in Figure 4. The measuring system differs from the system shown in Figure 2 in the following elements: 1-high-power programmable AC source with transients-Chroma 61510, 6-two PQ-Box 200 analysers (Chroma Systems Solutions, Foothill Ranch, CA, USA) (at the generator output and at 
the input of the manipulator automation supply), and a 7-DVR dynamic voltage restorer (AGH University of Science and Technology, Kracow, Poland) (prototype research unit).

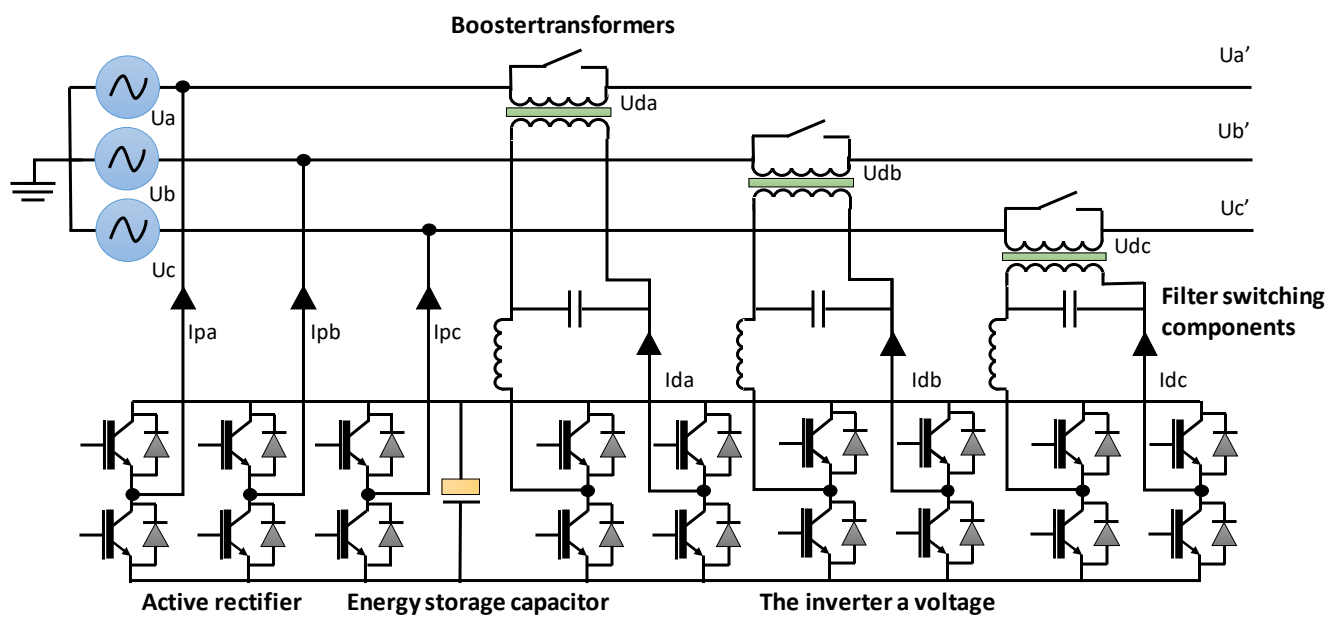

Figure 3. Schematic diagram of the DVR conditioner.
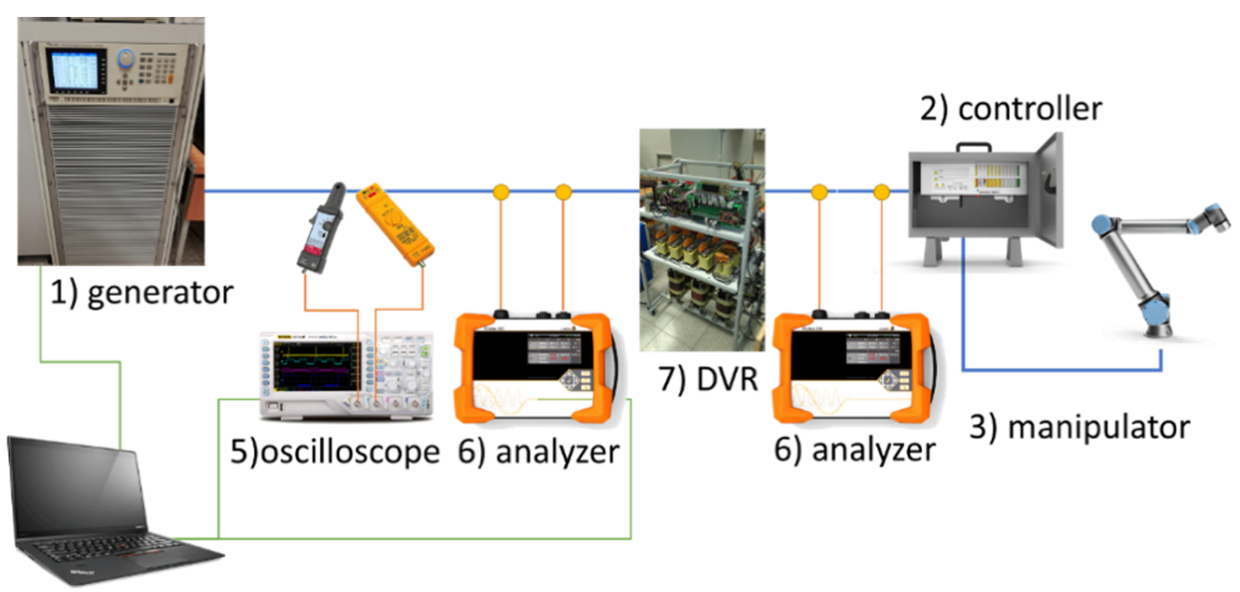

4) computer

(a)

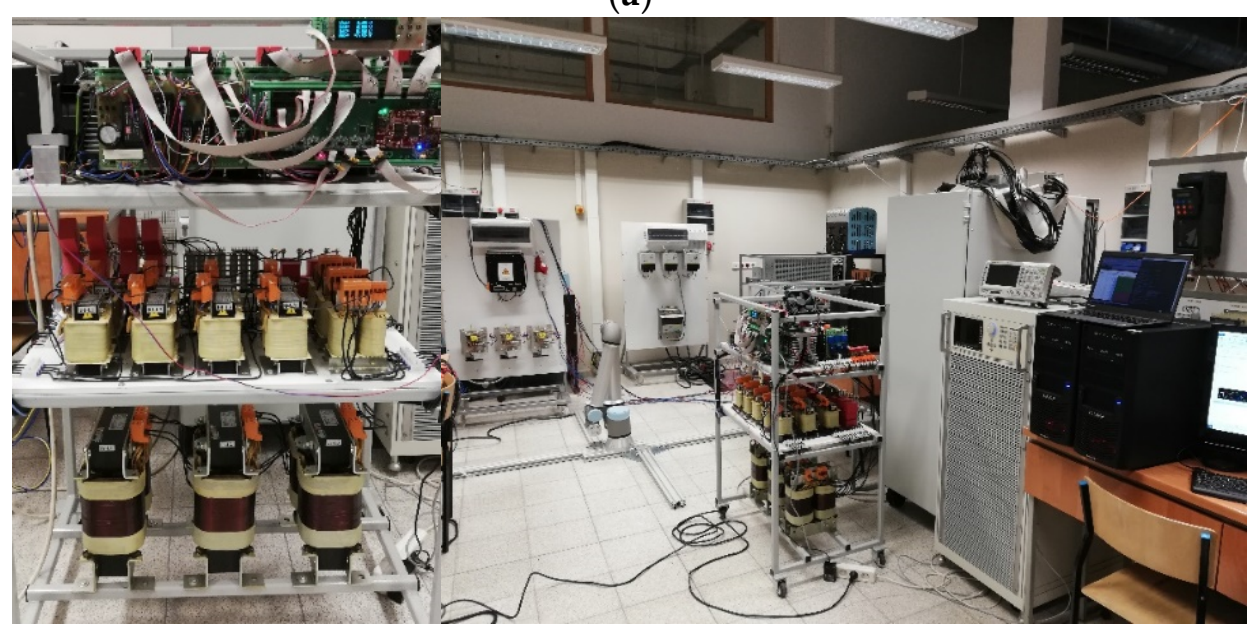

(b)

Figure 4. Schematic diagram (a) of the measuring system for tests with the use of a voltage conditioner and its practical implementation $(\mathbf{b})$. 
In the tested system, the power of the robot unit was connected to the secondary side of the DVR, while the primary side of the conditioner for single-phase tests (the Teseq NSG 1007 series generator) was used, and for the three-phase tests, the Chroma 61512 generator (Chroma Systems Solutions, Inc., Orange County, CA, USA) was used. Using the generator, dips were created that previously caused disturbances in the correct operation of the robot. In addition, a second electrical power-quality analyser was used in this system to compare the voltage at the DVR input and output.

As can be seen in the diagram, the DVR is connected in a series in the power supply circuit of the industrial robot. The DVR internal connection system consists of an active rectifier and three $\mathrm{H}$ inverters with a filter. The capacitor in the common DC bus acts as the energy storage for the additional voltage in the device [22]. System synchronisation with the network is ensured by the reference current system. In addition, in the case of high currents caused by an excessive load or short circuit, the DVR is equipped with by-pass connectors, which protect it against damage. Operation of the device seems to be simple; however, the development of effective control algorithms and control and measurement devices is a difficult issue and is the subject of much research [23].

\section{Results}

In order to prove the authenticity and effectiveness of the identification of the problem of the impact of dips on the operation of robotic sockets, it was decided in this study to measure the disturbances generated by an analyser with a measurement class in accordance with the IEC 61000-4-30 standard [1] and perform measurements with an oscilloscope. The quantitative assessment of the events and the analysis of the recorded waveforms were carried out in MATLAB.

\subsection{Tests without a Conditioner}

Registered events in the form of the emergency operation of selected robots that required a restart of the whole device are presented in Figure 5.

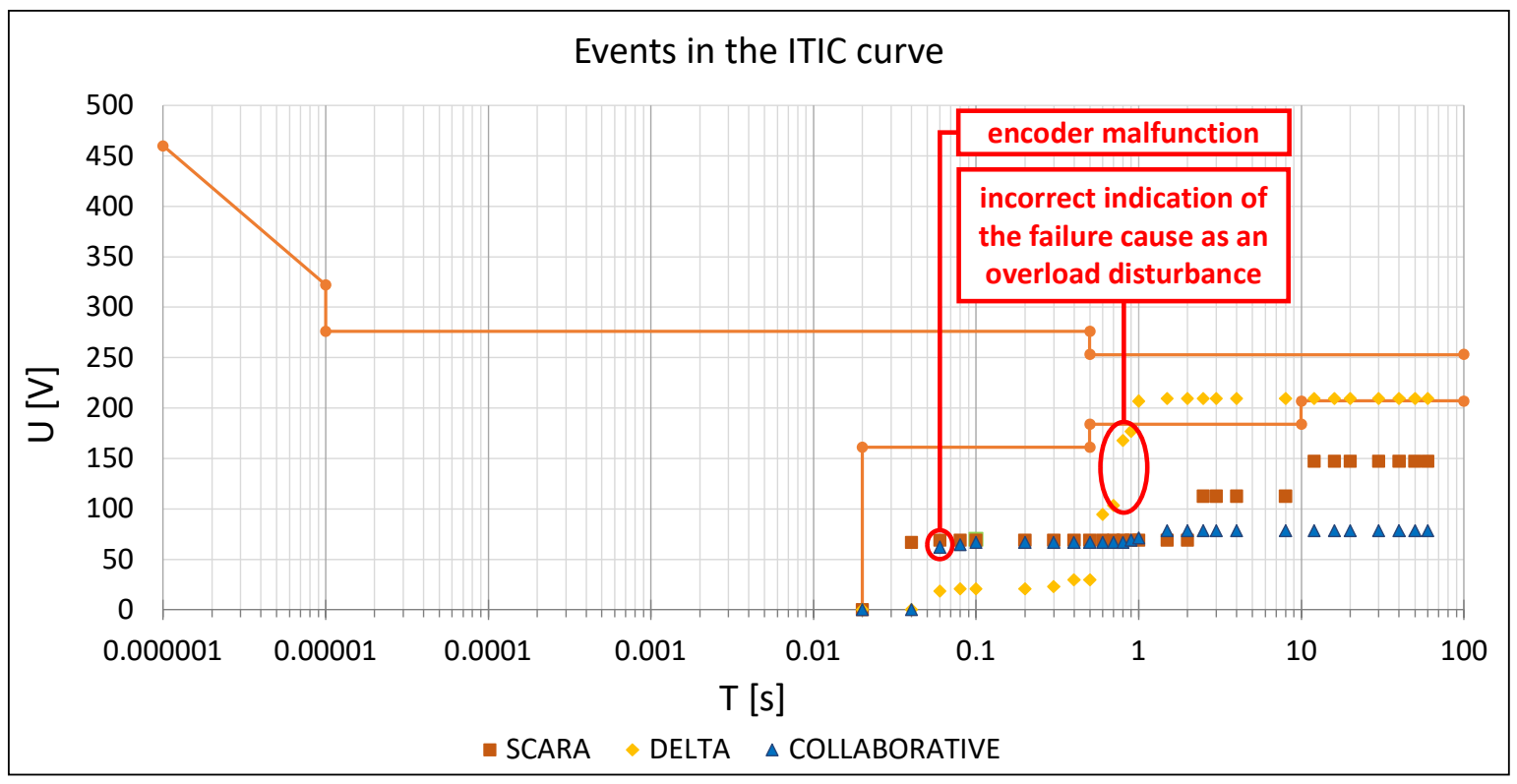

Figure 5. Disturbances in the correct operation of selected tested robots against the background of ITIC characteristics (in the region marked in ITIC/SEMI F47 as being free from destructive states, states leading to the destruction of the receiver have been identified).

Despite different types of units from the family of single-phase systems, states that may lead to damage to the receiver or its environment have been observed.

SCARA robots type: two joints move the axis up and down. 
Delta robots type: used for ceiling mounting. These consist of a base and arms holding the platform and a gripper.

Collaborative robots type: otherwise known as cobots-as the name suggests, these can work directly with humans.

The results of all of the measurements were recorded in the form of a matrix of voltage dip duration and depth; however, due to the size of the tables, the resistance curves for which the disturbance states of the robot's operation were marked (indicating key anomalies leading to damage) for the tested robots are presented in Figures 5 and 6. The tests show a significant deviation of the Delta robot from the other two. At the beginning, it can be wrongly stated that the reason for this is a static error of the biased estimator; however, this is not due to errors, but to the design of the robot controller itself. The results were presented to the controller manufacturer, who admitted that he also identified the problem and introduced a new type of controller to the market which improved the resistance of the manipulator to power disturbances.

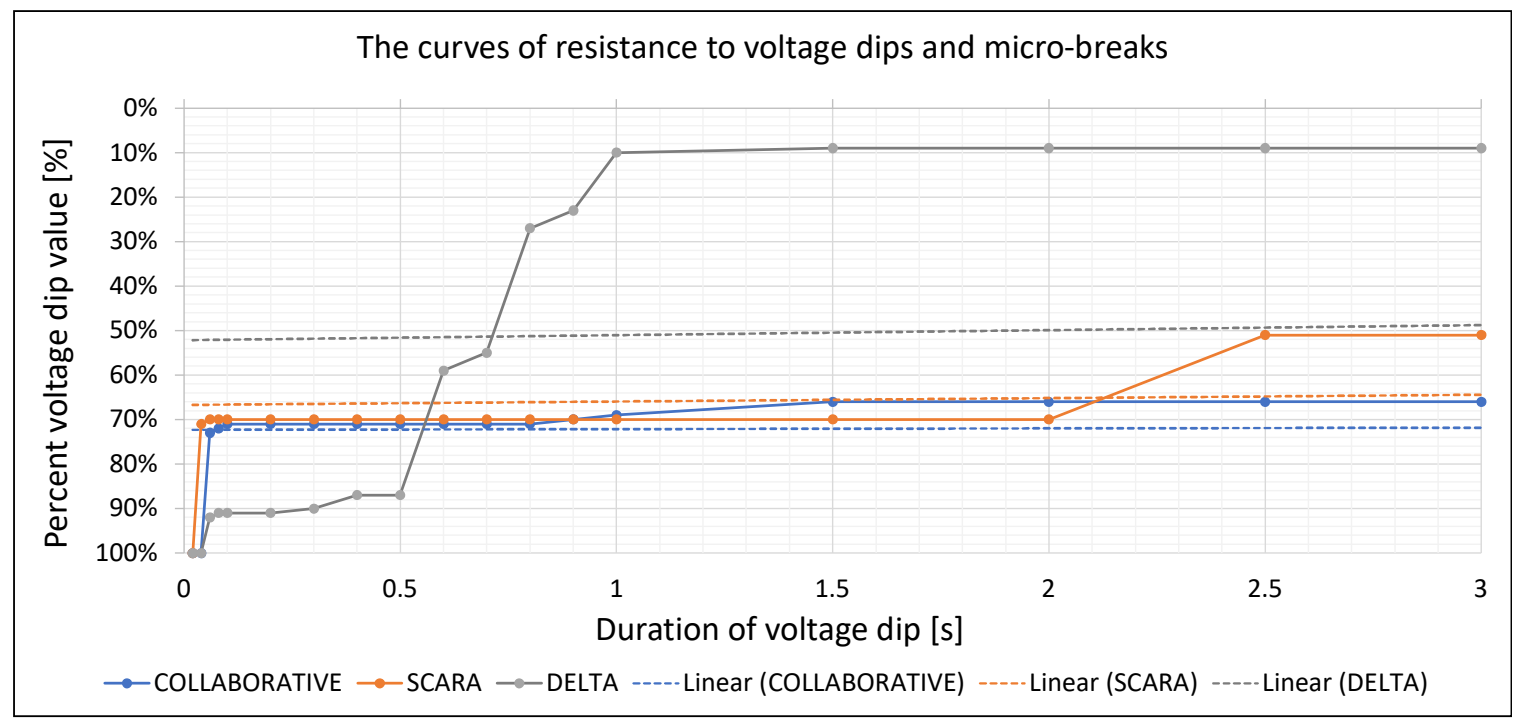

Figure 6. The robustness curves of individual robots for dips and micro-breaks in the power supply.

Surprisingly, but confirming the assumed thesis that in the area defined by the ITIC and SEMIF47 characteristics, appearing Figure 1 as the "No damage region", there are states leading to receiver damage and it was the presence of destructive disturbances in the area marked as " $\mathrm{A}$ " in Figure 1 which caused damage to the controller. Another significant error that can cause irreversible damage on the production line or in the vacuum systems is the loss of manipulator position on the encoders; a condition that has been detected in the region concerned.

\section{Tests with a Voltage Conditioner}

The authors are aware that there are many different methods of protection against the effects of voltage dips, such as shunt compensators, series compensators and shunt-series compensators. Nevertheless, the mere improvement of parameters is not the essence of the presented research. Unfortunately, the plan for further work on studying the impact of individual voltage conditioners was postponed due to the prevailing pandemic restrictions, which also tightened the formalities related to permits and arrangements for the installation of prototype conditioners in real facilities where disturbances occur. The waveforms presented below confirm the effectiveness and legitimacy of using the conditioner for an industrial process qualified by the authors to environmental class I, which must operate in a continuous mode. Below is the general formula for the receiver voltage using DVR, derived according to the diagram in Figure 3 [24]. 


$$
u_{a^{\prime}, r e f}(t)=U_{a^{\prime}, r e f} \sin \left(\omega t+\varphi_{a^{\prime}, r e f}\right)
$$

where: $U_{a^{\prime}, \text { ref }}$-load voltage designed amplitude, $\varphi_{a^{\prime}, \text { ref }}$-load shift angle relative to the supply voltage $[25,26]$.

The results of the measurements were found to be very promising. An example test is presented in Figure 7, where the graphs on the left show the generated one-phase and three-phase dip, and the waveforms on the right show the voltage waveform at the supply of the robot system. As you can see from the waveforms, the DVR performed a voltage sag compensation that previously caused the robot to reboot. Currently, the authors of this article are in the process of preparing new guidelines for testing and using power supply conditioners. The tests are aimed at identifying disturbances that still cause the malfunction of the robotic system despite compensation of the supply voltage parameters.

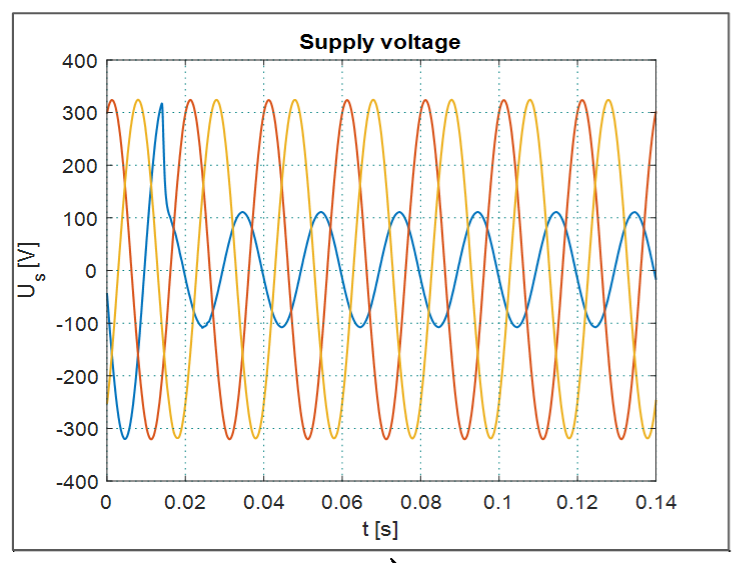

a)

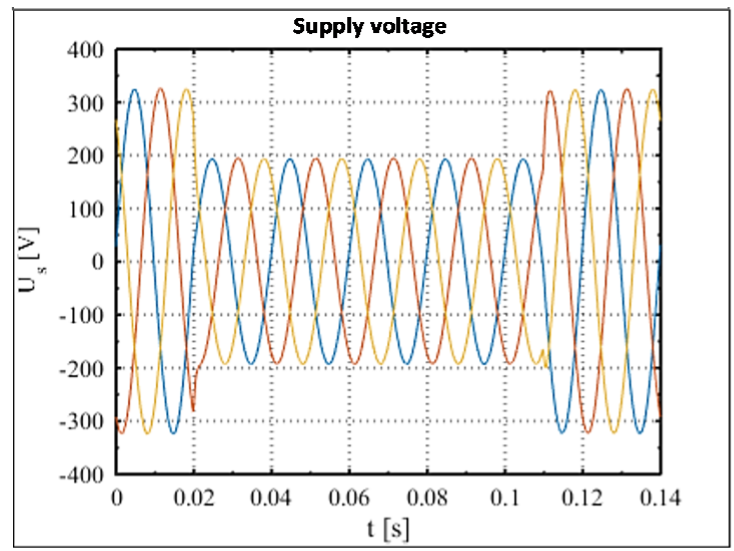

c)

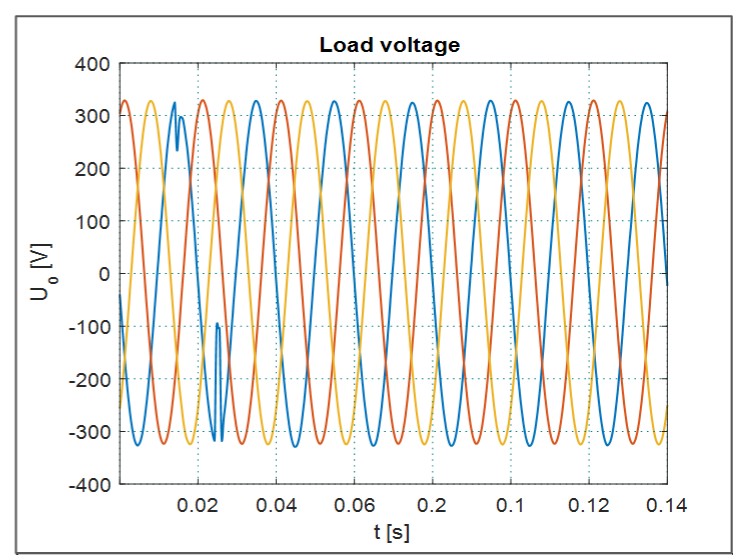

b)

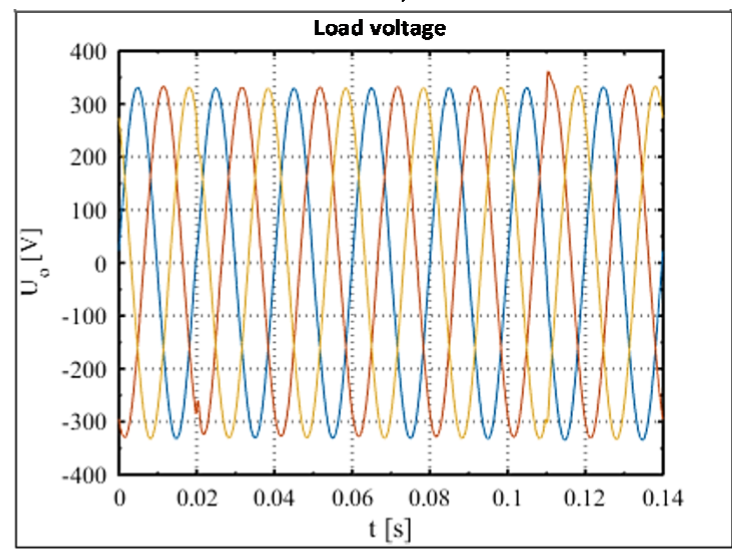

d)

Figure 7. Voltage registrations-the graphs on the left show the voltage from the mains, graphs on the right show the voltage from the robot's power supply. (a) one-fhase voltage dip; (b) voltage waveform at the supply robot behind DVR after one-phase voltage dip; (c) three-fhase voltage dip; (d) voltage waveform at the supply robot behind DVR after three-phase voltage dip.

\section{Conclusions}

As the results from the research presented in this article show, the process of designing robotic stations, including the selection of components of power electronics as well as assigning them a resistance class for disturbances, does not correspond to the current conditions in the power system. This is mainly caused by the increased number of disturbances introduced into the network by electrical power devices, such as inverters, and in 
recent years, also by renewable energy sources, which together with the development of semiconductor technologies have become common sources of disturbances.

At this point, it should be emphasised that the area of research into robots and their resilience is the domain of research teams who are manufacturing robotic units or scientists who are contracted by manufacturers, which significantly limits the development of knowledge in the field due to numerous corporate restrictions, including maintaining secrecy.

The authors indicate that the tests specified in the normative documents for production processes incorrectly classify the failure state in the group of events that do not affect damage to the receiver; these tests are aimed at confirming the resistance of the receiver to power quality disturbances, including the occurrence of voltage dips in combination with the erroneous interpretation of the type of disturbance on the receiver side. This is justified in order to introduce the recording of the voltage values in the receiver automation systems (especially industrial robots) and the correlation of their level with the current values because, as was established during the tests, the very registration of current overloads and voltages resulting from a voltage dip leads to erroneous conclusions. Therefore, it can be reasonably stated that the errors indicated during the immunity tests carried out on the basis of the currently applicable normative documents and guidelines, allow the placing on the market of devices that do not meet the requirements of resistance to energy quality disturbances (which is not the fault of the manufacturers themselves, as the tests are performed in accordance with normative requirements and a too narrow set of recorded parameters allows for errors in the interpretation and classification of disorders). Therefore, it is worth outlining the problem and investigating it at a deeper level in further research in order to also identify the discussed states in three-phase systems with higher power levels. Perhaps a simple solution to the problem would be the obligation to use undervoltage protection in power supply systems, which would allow for the rapid identification of the type of disturbance by correlating the voltage drop with the increase in current at the same time.

The collected quantity of measurement data from several types of industrial robots determines the need to broaden the base of the measurement results database to expand it with the addition of new models and other power systems. Bearing in mind the applicative character of the research results, it will be necessary to continue the work and constantly expand the measurement data resources for model improvement and the electromagnetic immunity characteristics of ITIC and SEMI F47 dedicated to industrial robots to work in the third class of EMC interferences. According to the presented results, the designers of production cycles, together with technicians, should take into account the requirements for feeding robotic sockets. The process class should define the requirements of the powersupply conditions with respect to the classification in normative documents as presented in this article.

The tests showed and confirmed the susceptibility of machines to failures within the range marked with a yellow frame on the ITCI characteristics in Figure 1. In the next stages of their research, the authors of this text plan to conduct tests using various conditioners and analyse their impact in an environment with a high concentration of robotic sockets, as well as the impact of interference in the extended band up to $150 \mathrm{kHz}$. Initial research and its continuation are planned in cooperation with The Laboratory of Electrical Power Quality of AGH, which is the leading research unit in the country dealing with the subject of power quality.

After conducting another series of studies on the cooperation of a robotic station with a DVR and an industrial UPS, the authors will present a series of articles on the properties of cooperation of robotic stations with individual power conditioners.

The authors juxtaposed the test results with the SEMI F47/ITIC characteristics that revealed destructive conditions for power receivers (20 ms-500 ms at a voltage dip above $70 \%$ ), in an area defined as being free from damage. Disturbances were also identified in the operation of the automation systems, including error loggers, which due to col- 
lapse, fail to record changes in the position of the robot arm in space (no registration of changes in the position of the encoders). This may result in unforeseen consequences of permanent damage to the unit or its environment, which is important for vacuum systems, which require special securing by additional electrical equipment. This is undoubtedly a significant discovery indicating the need to revise the current guidelines for researching the resistance of electrical receivers (including industrial robots and their equipment) to electricity disturbances.

It is worth emphasising that the use of compensation systems such as DVR, AVR, UPS, and DySc limit the identification of the source of the sags, although they actually compensate for disturbances in the form of voltage sags depending on the type of receiver (in this case, the robot type).

Author Contributions: Conceptualisation, G.P.; methodology, G.P. and K.W.; validation, E.S. and L.S.; data collection, K.W. and G.P. writing—original draft preparation, G.P. and K.W.; writing — review and editing, G.P. and K.W.; visualisation, K.W.; supervision E.S.; funding acquisition, G.P.; project administration, K.W. All authors have read and agreed to the published version of the manuscript.

Funding: This research was funded by the NCBiR (the National Centre for Research and Development in Poland) as part of the Intelligent Development Operational Program 2014-2020, measure 4.1: Research and development Sub-measure 4.1.2 “Regional science and research agendas" POIR.04.01.0200-0045/18, The title of the project is "Development and demonstration of robotic bricklaying and plastering system (ZSMT) for use in the construction industry".

Acknowledgments: We would like to thank Mitsubishi Electric Europe B.V. (Poland branch) as well as Universal Robots and the distributor Elmark Automatyka S.A. for support in providing industrial robots and laboratory facilities. We would also like to thank the Energy Centre of the AGH University of Science and Technology in Krakow for providing laboratories and research equipment, in particular the Electric Power Quality Laboratory Team, as well as the Electric Power Quality Laboratory at the Faculty of Electrical Engineering, Automatics, Computer Science and Biomedical Engineering.

Conflicts of Interest: The authors declare no conflict of interest. 


\section{Appendix A. Matrix of Process/Environmental Classes with Reference to Standard Power Quality Documents}

\begin{tabular}{|c|c|c|c|c|c|c|c|c|c|c|}
\hline \multirow[b]{2}{*}{$\begin{array}{l}\text { Environme } \\
\text { Class }\end{array}$} & \multirow[b]{2}{*}{$\begin{array}{l}\text { Process Require- } \\
\text { ments/Operating } \\
\text { Mode }\end{array}$} & \multirow[b]{2}{*}{ Requirements for Robotic System } & \multirow[b]{2}{*}{ Additional Equipment } & \multicolumn{6}{|c|}{ Occurrence } & \multirow[b]{2}{*}{$\begin{array}{l}\text { Normative } \\
\text { Document }\end{array}$} \\
\hline & & & & $\begin{array}{l}\text { Frequency } \\
\text { Deviation }\end{array}$ & $\begin{array}{l}\text { Voltage Dips } \\
\Delta \text { U/Un Number } \\
\text { Half-Cycles }\end{array}$ & $\begin{array}{l}\text { Short Breaks in } \\
\text { Power }\end{array}$ & $\begin{array}{l}\text { Uneg/Upos } \\
\text { Voltage } \\
\text { Unbalance } \\
\text { for Average } \\
\text { over } 10 \text { min. }\end{array}$ & Flickeı & $\begin{array}{l}\text { THD Average } \\
\text { over } 10 \mathrm{~min} .\end{array}$ & \\
\hline \multirow[t]{2}{*}{ I } & \multirow{2}{*}{$\begin{array}{l}\text { Required work } \\
\text { stability in the } \\
\text { process in which } \\
\text { the robot is } \\
\text { installed } \\
\text { (continuous } \\
\text { operation without } \\
\text { switching off the } \\
\text { system) }\end{array}$} & \multirow{2}{*}{$\begin{array}{l}\text { - Separated robot supply circuits } \\
\text { Accessories that meet the } \\
\text { requirements for class } 1 \\
\text { disturbances in accordance } \\
\text { with PN-EN 61000-2-4 } \\
\text { Uninterrupted operation in } \\
\text { monitoring power parameters } \\
\text { to identify disturbances in the } \\
\text { mains. }\end{array}$} & \multirow{2}{*}{$\begin{array}{l}\text { Backup power supply and } \\
\text { accessories in the form of voltage } \\
\text { conditioners such as: } \\
\text { DVR, AVR, DySC, } \\
\text { UPS online, } \\
\text { - Reduction of cross-emission } \\
\text { in the robotic environment } \\
\text { Passive and active filters }\end{array}$} & $\begin{array}{c}\text { in class } 1 \text { and } 2 \\
\pm 1 \%\end{array}$ & $\begin{array}{c}\text { in class } 1 \\
1 \text { half-period }\end{array}$ & $\begin{array}{c}\text { in class } 1 \\
\text { no occurrence }\end{array}$ & $\begin{array}{c}\text { in class } 1 \text { and } \\
2 \\
\pm 2 \%\end{array}$ & 1 & $\begin{array}{c}\text { in class } 1 \\
5 \%\end{array}$ & $\begin{array}{l}\text { PN-EN } \\
61000-2-4\end{array}$ \\
\hline & & & & $\begin{array}{c} \pm 1 \% \text { (average for } \\
10 \text { s by } 99.5 \% \\
\text { year), } \\
6 \% \div 4 \% \text { by } 100 \% \\
\text { of the year } \\
\text { insulated } \\
\text { respectively } \\
2 \% \text { and } 15 \% \\
\end{array}$ & $\begin{array}{c}(5-90) \% \text { Dips } \\
\text { in } 5 \text { patterns } \\
\text { at intervals } \\
(10-200>\mathrm{ms}, \\
(0.2-0.5>\mathrm{s}, \\
(0.5-1>\mathrm{s}, \\
(1-5>\mathrm{s}, \\
(5-60>\mathrm{s} \\
\end{array}$ & $\begin{array}{l}\text { Classified on the } \\
\text { basis of } \\
\text { characterisation } \\
\text { statistics, e.g., } \\
\text { UNIPEDE }\end{array}$ & $\leq 2 \%$ & 1 & $8 \%$ & PN-EN 50160 \\
\hline \multirow[t]{2}{*}{ II } & \multirow{2}{*}{$\begin{array}{l}\text { Required work } \\
\text { stability in the } \\
\text { process in which } \\
\text { the robot is } \\
\text { installed (work in } \\
\text { the process in } \\
\text { intermittent cycles, } \\
\text { where there is a } \\
\text { break in operation } \\
\text { between cycles, } \\
\text { where there is } \\
\text { another } \\
\text { non-automated } \\
\text { operation } \\
\text { between). }\end{array}$} & $\begin{array}{l}\text { - Separated robot supply circuits } \\
\text { Accessories that meet the } \\
\text { requirements for class } 1 \\
\text { disturbances in accordance } \\
\text { with PN-EN 61000--2-4 } \\
\text { Uninterrupted operation in } \\
\text { monitoring power parameters } \\
\text { to identify disturbances in the } \\
\text { mains. }\end{array}$ & $\begin{array}{l}\text { Backup power supply and } \\
\text { accessories in the form of voltage } \\
\text { conditioners such as: } \\
\text { DVR, AVR, DySC, } \\
\text { - } \quad \text { Red online, } \\
\text { in the robotic envicemission } \\
\text { - Passive and active filters }\end{array}$ & $\begin{array}{c}\text { in class } 1 \text { and } 2 \\
\pm 1 \%\end{array}$ & $\begin{array}{c}\text { in class } 2 \text { and } 3 \\
1-300 \\
\text { half-cycles }\end{array}$ & $\begin{array}{l}\text { in class } 2 \text { none } \\
\text { undefined }\end{array}$ & $\begin{array}{c}\text { in class } 1 \text { and } \\
2 \\
\pm 2 \%\end{array}$ & 1 & $\begin{array}{c}\text { in class } 1 \\
8 \%\end{array}$ & $\begin{array}{l}\text { PN-EN } \\
61000-2-4\end{array}$ \\
\hline & & $\begin{array}{ll}\text { - } & \text { Equipment with 2nd class } \\
\text { EMC resistance (PN-EN } \\
\text { 61000-2-4 including operation } \\
\text { in disturbed environments) } \\
\text { - Functionality and equipment } \\
\text { compatible } \\
\text { - Monitoring of work } \\
\text { parameters, including power } \\
\text { supply conditions }\end{array}$ & $\begin{array}{ll}\bullet & \text { Backup power (UPS) } \\
: & \text { Passive filters } \\
& \text { Cyclic zeroing } \\
& \text { Optimisation procedure }\end{array}$ & $\begin{array}{l} \pm 1 \% \text { (average for } \\
10 \text { s by } 99.5 \% \\
\text { year), } \\
6 \% \div 4 \% \text { by } 100 \% \\
\text { of the year } \\
\text { insulated } \\
\text { respectively } \\
2 \% \text { and } 15 \%\end{array}$ & $\begin{array}{c}(5-90) \% \text { Dips } \\
\text { in } 5 \text { patterns } \\
\text { at intervals } \\
(10-200>\mathrm{ms}, \\
(0.2-0.5>\mathrm{s}, \\
(0.5-1>\mathrm{s}, \\
(1-5>\mathrm{s}, \\
(5-60>\mathrm{s}\end{array}$ & $\begin{array}{l}\text { Classified on the } \\
\text { basis of } \\
\text { characterisation } \\
\text { statistics, e.g., } \\
\text { UNIPEDE }\end{array}$ & $\leq 2 \%$ & 1 & $8 \%$ & PN-EN 50160 \\
\hline \multirow[t]{2}{*}{ III } & \multirow{2}{*}{$\begin{array}{l}\text { Required work } \\
\text { stability in the } \\
\text { execution cycle } \\
\text { (individual } \\
\text { process, where the } \\
\text { robot performs a } \\
\text { specific action in } \\
\text { the entire } \\
\text { non-automatic } \\
\text { process) }\end{array}$} & \multirow{2}{*}{$\begin{array}{ll}\text { - } & \text { Equipment with basic EMC } \\
\text { resistance class (including } \\
\text { work in disturbed } \\
\text { environments, 3rd class of } \\
\text { resistance PN-EN 610002-4) } \\
\text { Functionality and equipment } \\
\text { compatible }\end{array}$} & \multirow{2}{*}{$\begin{array}{ll}\bullet & \text { Passive filters } \\
& \text { Cyclic zeroing } \\
& \text { Optimisation procedure }\end{array}$} & $\begin{array}{c}\text { in class } 3 \\
\pm 2 \%\end{array}$ & $\begin{array}{c}\text { in class } 2 \text { and } 3 \\
1-300 \\
\text { half-cycles }\end{array}$ & $\begin{array}{l}\text { in class } 3 \\
\text { less than } 60\end{array}$ & $\begin{array}{c}\text { in class } 3 \\
\pm 3 \%\end{array}$ & 1 & $\begin{array}{c}\text { in class } 1 \\
10 \%\end{array}$ & $\begin{array}{l}\text { PN-EN } \\
61000-2-4\end{array}$ \\
\hline & & & & $\begin{array}{c} \pm 1 \% \text { (average for } \\
10 \text { s by } 99.5 \% \\
\text { year), } \\
6 \% \div 4 \% \text { by } 100 \% \\
\text { of the year } \\
\text { insulated } \\
\text { respectively } \\
2 \% \text { and } 15 \% \\
\end{array}$ & $\begin{array}{c}(5-90) \% \text { Dips } \\
\text { in 5 patterns } \\
\text { at intervals } \\
(10-200>\mathrm{ms}, \\
(0.2-0.5>\mathrm{s}, \\
(0.5-1>\mathrm{s}, \\
(1-5>\mathrm{s}, \\
(5-60>\mathrm{s} \\
\end{array}$ & $\begin{array}{l}\text { Classified on the } \\
\text { basis of } \\
\text { characterisation } \\
\text { statistics, e.g., } \\
\text { UNIPEDE }\end{array}$ & $\leq 2 \%$ & 1 & $8 \%$ & PN-EN 50160 \\
\hline
\end{tabular}




\section{References}

1. IEC 61000-2-4:2002. Electromagnetic Compatibility (EMC)—Part 2-4: Environment—Compatibility Levels in Industrial Plants for Low-Frequency Conducted Disturbances. Available online: https:/ / webstore.iec.ch/publication/4135 (accessed on 26 June 2020).

2. Küfeoglu, S.; Lehtonen, M. Macroeconomic Assessment of Voltage Sags. Sustainability 2016, 8, 1304. [CrossRef]

3. Misbakhov, R.; Bakhteev, K. Influence of Voltage Dips on the Stability of Excitation of Synchronous Machines. In Proceedings of the 2019 20th International Scientific Conference on Electric Power Engineering (EPE), Kouty nad Desnou, Czech Republic, 15-17 May 2019; pp. 1-7. [CrossRef]

4. Galceran, S.; Teixidó, M.; Sumper, A.; Casas, J.; Sánchez, J. Adjustable Speed Drives and Power Quality. In Proceedings of the International Conference on Renewable Energies and Power Quality (ICREPQ), Vigo, Spain, 9-12 April 2003; Volume 364, pp. 256-261.

5. Honrubia-Escribano, A.; Gomez-Lazaro, E.; Molina-Gracia, A.; Fuentes, J.A. Influence of voltage dips on industrial equipment. Int. J. Electr. Power Energy Syst. 2012, 41, 87-95. [CrossRef]

6. Łukasik, Z.; Kuśmińska-Fijałkowska, A.; Kozyra, J.; Putynkowski, G.; Woźny, K. The problem of power supply for station with industrial robot in an automated welding process. Electr. Eng. 2017, 100, 1365-1377. [CrossRef]

7. Carbone, G.; Ceccarelli, M.; Fabrizi, C.; Varilone, P.; Verde, P. Effects of Voltage Dips on Robotic Grasping. Robotics 2019, 8, 28. [CrossRef]

8. Missala, T. Model oddziaływań EMC w gnieździe zrobotyzowanym. Prz. Elektrotech. 2012, 88, 1-3.

9. Putynkowski, G.; Balawender, P.; Woźny, K.; Kozyra, J.; Łukasik, Z.; Kuśmińska-Fijałkowska, A.; Ciesielka, E. A new model for the regulation of distribution system operators with quality elements that include the SAIDI/SAIFI/CRP/CPD indices. Electr. Power Qualty Util. 2016, 19, 1-10.

10. PN-EN 50160:2010/A2:2019-11-Wersja Angielska. Available online: https://sklep.pkn.pl/pn-en-50160-2010-a2-2019-11e.html (accessed on 21 November 2019).

11. International Electrotechnical Commission. EN 50160:2010/A2:2019. Voltage Characteristics of Electricity Supplied by Public Electricity Networks. Available online: https:/ / standards.iteh.ai/catalog/standards/clc/9044cbd4-1485-45e1-8fe1-5e36dcac244 0/en-50160-2010-a2-2019 (accessed on 20 September 2019).

12. Minister of Economy. Ordinance of the Minister of Economy on the detailed conditions for the operation of the power system of May 4, 2007. J. Laws 2007, 93, item 623.

13. International Electrotechnical Commission. EN 61000-2-4:2003/AC:2015. Electromagnetic Compatibility (EMC)—Part 2-4: Environment-Compatibility Levels in Industrial Plants for Low-Frequency Conducted Disturbances. Available online: https: / / standards.iteh.ai/catalog/standards/clc/226f3427-34fb-447b-a73c-51ec3addbb45/en-61000-2-4-2002 (accessed on 16 March 2015).

14. Piątek, K. Zastosowanie Szeregowych Energetycznych Filtrów Aktywnych Do Poprawy Jakości Dostaw Energii Elektrycznej. Ph.D. Thesis, AGH University of Science and Technology, Krakow, Poland, 2016.

15. Szychta, L.; Szychta, E.; Kiraga, K. Efficiency of Induction Heating of Rails with Oblong Heaters. In Telematics in the Transport Environment, Communications in Computer and Information Science, Proceedings of the 12th International Conference on Transport Systems Telematics, Katowice-Ustron, Poland, 10-13 October 2012; Mikulski, J., Ed.; Springer: Berlin, Germany, 2012; pp. 328-333. [CrossRef]

16. Szychta, L.; Szychta, E.; Wiak, S. Nonintrusive Method of Residual Losses Estimation in Squirrel Cage Induction Motors. In Proceedings of the 2017 18th International Symposium on Electromagnetic Fields in Mechatronics, Electrical and Electronic Engineering (ISEF), Łódź, Poland, 14-16 September 2017; pp. 1-2. [CrossRef]

17. Kaniewski, J.; Szczesniak, P.; Jarnut, M.; Benysek, G. Hybrid Voltage Sag/Swell Compensators. IEEE Ind. Electron. Mag. 2015, 9 , 37-48. [CrossRef]

18. NorHasmaini, K.M.; MohamadHasmaini, M. Digital simulation of uninterruptible power supply (UPS) and Dynamic Voltage Restorer (DVR) for voltage sag mitigation. In Proceedings of the Australasian Universities Power Engineering Conference 2001 (AUPEC), Perth, Australia, 23-26 September 2001.

19. Grebers, R.; Gadaleta, M.; Paugurs, A.; Senfelds, A.; Avotins, A.; Pellicciari, M. Analysis of the energy consumption of a novel DC power supplied industrial robot. In Procedia Manufacturing, Proceedings of the 27th International Conference on Flexible Automation and Intelligent Manufacturing (FAIM), Moderna, Italy, 27-30 June 2017; Procedia Manufacturing; Elsevier: Amsterdam, The Netherlands, 2017; Volume 11, pp. 311-318. [CrossRef]

20. Brezovnik, R.; Cernelic, J.; Petrun, M.; Dolinar, D.; Ritonja, J. Impact of the Switching Frequency on the Welding Current of a Spot-Welding System. IEEE Trans. Ind. Electron. 2017, 64, 9291-9301. [CrossRef]

21. Saadeh, O.; Al Nawasrah, A.; Dalala, Z. A Bidirectional Electrical Vehicle Charger and Grid Interface for Grid Voltage Dip Mitigation. Energies 2020, 13, 3784. [CrossRef]

22. Senfelds, A.; Vorobjovs, M.; Meike, D.; Bormanis, O. Power Smoothing Approach within Industrial DC Microgrid with Supercapacitor Storage for Robotic Manufacturing Application. In Proceedings of the 2015 IEEE International Conference on Automation Science and Engineering (CASE), Gothenburg, Sweden, 24-28 August 2015; pp. 1333-1338. [CrossRef]

23. Muñoz-Cruzado-Alba, J.; Villegas-Núñez, J.; Vite-Frías, J.A.; Carrasco Solís, J.M. A New Fast Peak Current Controller for Transient Voltage Faults for Power Converters. Energies 2016, 9, 1. [CrossRef] 
24. Sakthivel, C.; Venkatesan, T.; Jethose, V.; Guruprasath, V.R. Modeling and simulation of bidirectional AC-DC power converter. In Proceedings of the 2nd International Conference on Inventive Systems and Control (ICISC), Coimbatore, India, 19-20 January 2018; pp. 1452-1455. [CrossRef]

25. Piątek, K.; Kołek, K.; Firlit, A. Rapid Controller Development for a Dynamic Voltage Restorer. In Proceedings of the International Symposium ELMAR, Zadar, Croatia, 18-20 September 2017; pp. 237-240. [CrossRef]

26. Voltage Sag Solutions for Industrial Customers-myTNB. Available online: https://www.mytnb.com.my/themes/user/mytnb/ docs/New\%20Power\%20Quality\%20Handbook\%202019.pdf (accessed on 9 September 2018). 